\title{
PHYSICOCHEMICAL ESTIMATION OF ALDOSTERONE IN URINE ${ }^{1}$
}

\author{
BY ROBERT NEHER AND ALBERT WETTSTEIN
}

(From the Research Laboratories of CIBA Limited, Basle, Switzerland)

(Submitted for publication December 27, 1955; accepted March 28, 1956)

We have recently described (2) the essential features of a physicochemical method for the specific determination of aldosterone in body fluids and tissues. This method has become of special interest to clinical groups, particularly for the determination in urine. In the meantime, it has been possible to improve and simplify the method over several hundred determinations, so that it is now suitable, as a standardized procedure, for use in routine clinical investigations of urine. These reasons prompt us to publish the following modified and detailed description, so that the delicate procedure should be perfectly reproducible.

The method consists of three steps : 1 . Hydrolysis and extraction of the urine, 2. paper chromatography of the extracts with the help of two solvent systems, in which the relative running rates of aldosterone can be differentiated from those of other corticosteroids, and 3. semiquantitative estimation of the aldosterone.

\section{MATERIALS}

Methanol: distilled; Ethyl acetate: distilled.

Acetone: shaken with calcium chloride, filtered and distilled.

Chloroform: washed with water, shaken with calcium chloride, filtered and distilled.

Toluene: emulsified three times with 0.07 vol. of conc. sulphuric acid at room temperature in a Vibro-mixer for five minutes, separated, washed 5 times with 0.2 vol. of water to neutral, dried over phosphorus pentoxide and distilled in vacuo.

Light petroleum : distilled, fraction with b.p. $50-70^{\circ} \mathrm{C}$.

Formamide: Merck, chromatographic grade.

Whatman paper No. 1 (for preparative chromatogram) : extracted in a Soxhlet apparatus for 2 days with 95 per cent methanol and subsequently for 2 days with chloroform.

Sudan III : saturated solution in hexane.

Alkaline blue tetrazolium solution: mixture of 10 parts 0.1 per cent aqueous solution of blue tetrazolium (B.D.H., London) and 90 parts $2 \mathrm{~N}$ sodium hydroxide solution; may be stored for 1 to 2 days.

1 Communication No. 138 "On Steroids." No. 137 compare (1).
Reference substances: The solutions of cortisone and hydrocortisone in methanol should be stored (for not longer than 2 weeks) in small tubes with a double stopper, only the outer stopper being greased. Aldosterone solutions are unnecessary.

\section{METHOD}

\section{Urine sample}

The urine is cooled and collected over a 24 hour period with addition of about $10 \mathrm{ml}$. chloroform. If working up is not possible at once, the urine is frozen and stored at about $-10^{\circ} \mathrm{C}$. In general, at least half of the urine collected during 24 hours should be used; if a high aldosterone content is expected, correspondingly smaller amounts will suffice.

\section{Hydrolysis and extraction}

The urine is acidified to $\mathrm{pH} 1.5$ with conc. $\mathrm{HCl}$ at 10 to $15^{\circ} \mathrm{C}$. After standing for 24 hours at 15 to $20^{\circ} \mathrm{C}$., the extraction is carried out in a separating funnel fitted with a stirrer.

Thus, 1 vol. urine is stirred 4 times with 0.2 vol. chloroform for 15 to 20 minutes at room temperature, in such a way that good mixing of the two phases occurs without formation of emulsions separable only by centrifuging. The combined chloroform solutions $(=1$ vol.) are washed first with 0.05 vol. cold $0.1 \mathrm{~N}$ sodium hydroxide solution, then three times with 0.05 vol. water. The washings are twice back extracted with 0.05 vol. chloroform. All the chloroform solutions are now combined, dried quickly over a small amount of sodium sulphate, filtered, and evaporated in vacuo not over $50^{\circ} \mathrm{C}$. If a capillary-leak is used, this should be with nitrogen. The residue is dissolved in a little acetone, the solution filtered through a small cotton-wool pad into a weighed test tube and again evaporated in vacuo. This solution is dried at $60^{\circ} \mathrm{C}$. for about $1 / 2$ hour in vacuo and weighed.

On average, these extracts of 12 to 24-hour 
urine specimens weigh 10 to $60 \mathrm{mg}$., and are suitable for preparative paper chromatography without further purification. Should the extracts in special cases exceed this amount, they must be first chromatographed on silica-gel, as described earlier (2).

\section{Preparative paper chromatography}

One to five sheets of washed Whatman paper No. 1 (see Figure 1) are drawn through a 30 per cent solution of formamide in acetone, and allowed to hang for 5 minutes from the upper edge. After this time, the impregnated paper is ready to receive the chloroform extract. About 10 to $12 \mathrm{mg}$. of this is dissolved in $0.1 \mathrm{ml}$. methanol-chloroform $(1: 1)$, and distributed in a line on each sheet, by moving the micropipette backwards and forwards evenly over the start line, keeping the outflow rate as constant as possible. The test tube is rinsed three times with $0.02 \mathrm{ml}$. solvent, and this solution also distributed over the sheets. A space of $3.5 \mathrm{~cm}$. is left free in the midle of one of the sheets where the reference substances, $10 \mu \mathrm{g}$. of cortisone and hydrocortisone, respectively, in 0.2 per cent methanol solution, are dropped on. Two to five $\mu$ l. of a solution of Sudan III may be dropped on one end of the start line, this indicator moving with the solvent front. The chromatograms are developed by the descending technique at a constant temperature (e.g., 20 to $22^{\circ} \mathrm{C}$.) using chloroform saturated with formamide (3). Paper chromatographic practice must be assumed here, and will not be described further. See e.g. the general reviews of Cramer (4), and of Block, Durrum, and Zweig (5), the papers of Zaffaroni (3) and Bush (6), and the references given therein. By the procedure outlined above, the solvent front reaches the bottom in 2.5 to 3 hours. The sheets are carefully removed from the trough and allowed to dry, preferably overnight, at room temperature and protected from light.

\section{U.V. photocopying and evaluation}

The chromatograms are notched on one side, spread over photographic paper in the dark room (Markham and Smith [7]), and illuminated at a distance of 35 to $40 \mathrm{~cm}$. by a U.V. lamp for 4 to 5 seconds, with the aid of a shutter on the underside of the lamp housing (light source: GE Germicidal

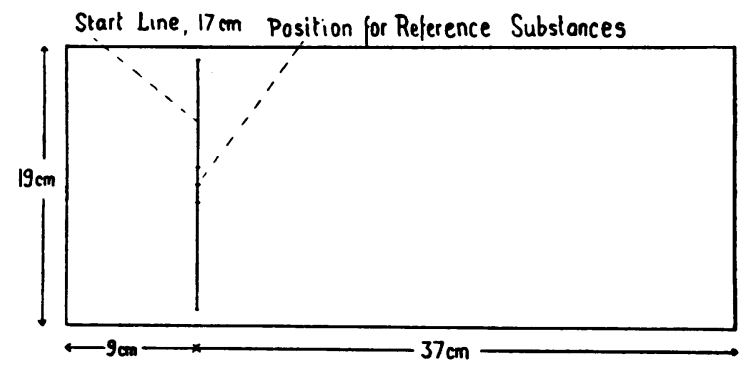

Fig. 1. Diagram of Paper Sheet Used in Chromatography

Lamp, 8 watt, without filter). The exposed photographic papers are developed, fixed, washed and dried in the usual way.

In the formamide/chloroform system, aldosterone travels almost as far as cortisone. A line is therefore drawn across the reference photo-copy at the lower limit of the cortisone spot, and a parallel one about $5 \mathrm{~cm}$. above it. The location of cortisone and aldosterone on the photo-copies of the chromatograms without the reference substances can easily be established by comparison with the first sheet. For this purpose the pattern on the photo-copy formed by the accompanying U.V.-absorbing material is very useful. For example, there is often a strongly absorbing band just ahead of the cortisone, but which has nothing to do with either cortisone or aldosterone. The chromatograms are now lined up with the corresponding photo-copy, and the two lines traced on the chromatograms. The bands thus marked, containing as hormones only cortisone and aldosterone, are cut out. The cortisone chromatographed jointly as a reference substance does not affect the determination since it is separated, together with the urine cortisone, from the aldosterone in the following chromatogram.

\section{Elution of the paper strips containing aldo- sterone}

a) The strips removed are cut up and shaken with sufficient 20 per cent methanol in a glassstoppered round-bottomed flask to obtain a thick pulp. After standing for half an hour at room temperature, the solution is sucked through a sintered glass filter into another flask and the pulp residue slowly washed twice with methanol and pressed out. The filtrate is concentrated in 
vacuo (below $60^{\circ}$ C.) to about $1 / 5$ of its volume and shaken 3 times with half its resulting volume of chloroform. The combined filtered chloroform solutions are evaporated in vacuo. The acetone-soluble part of the residue is transferred to a small test tube that has been weighed exactly to $0.05 \mathrm{mg}$., and dried at 60 to $70^{\circ} \mathrm{C}$. in high vacuum for one-half to one hour, until all volatile substances have been removed (e.g., formamide from the chromatography), then weighed. At this stage the extracts weigh about 0.5 to $4 \mathrm{mg}$. per 12 to 24-hour urine volume.

b) A somewhat simpler elution procedure may be used just as effectively. The paper strips cutout are attached singly in $5 \mathrm{~cm}$. broad syphons ${ }^{2}$ made of aluminum sheet and packed with glass wool as shown in Figure 2a. The syphon is put into a shallow dish filled with 80 per cent methanol. Before the solvent front has reached the lower edge of the paper strip, a three-cornered piece of filter paper (Whatman No. 1), saturated with 80 per cent methanol, is hung on this to facilitate the draining of the solvent (Figure 2b). For complete elution, at least $15 \mathrm{ml}$. of solvent is allowed to run off for at least half an hour into a small round-bottomed flask, the whole being protected from draughts. The eluate is then evaporated in vacuo and taken up in a small quantity of acetone, the soluble part being filtered through a small cotton-wool pad into a weighed test-tube and treated as described in a). In recovery experiments it was found that by both methods about 90 and 95 per cent, respectively, out of 5 and $20 \mu \mathrm{g}$. aldosterone on the paper could be eluted. When it is necessary to elute several strips together,

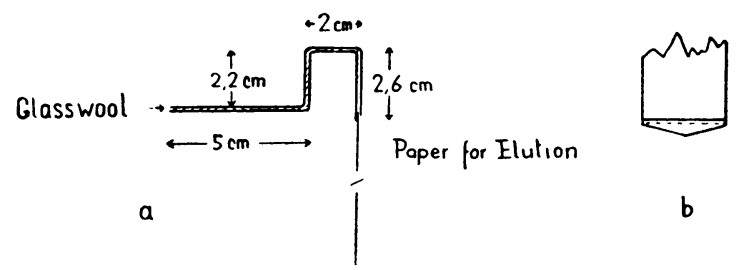

Fig. 2. Diagram of Aluminum Syphon Used for Elution

a-Side view.

b-Three-cornered paper tab saturated with 80 per cent methanol attached to the end of the strip to facilitate draining of the solvent.

${ }^{2}$ Suggested by Miss M. L. Helmreich, Salt Lake City.

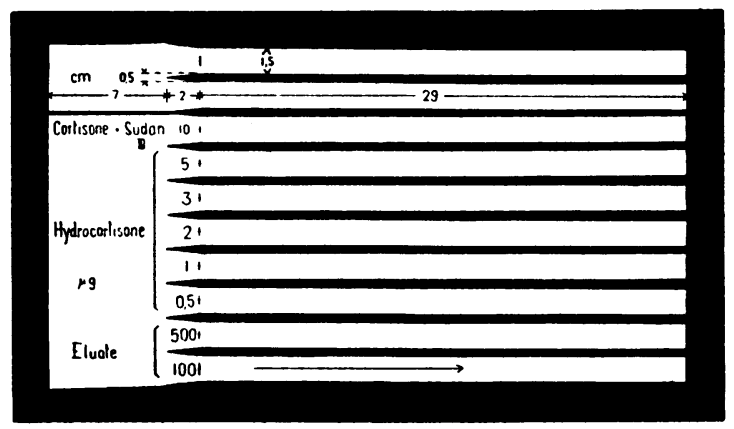

Fig. 3. Diagram of Arrangement of Paper Strips Employed in the Separation of Aldosterone by the Second Paper Chromatography

method a) is preferable. The latter also gives purer eluates, which may be advantageous in the second chromatography.

\section{Separation and estimation of aldosterone by the second paper chromatography}

From the extracts obtained above, $100 \mu \mathrm{g}$. and $500 \mu \mathrm{g}$., and also-if the amount of extract permits or the low aldosterone content necessitates$1,000 \mu \mathrm{g}$., are run by descending technique in Bush's system $C$ (6) parallel with $0.5,1,2,3$, and $5 \mu \mathrm{g}$. of hydrocortisone and $10 \mu \mathrm{g}$. cortisone.

Example. $1.7 \mathrm{mg}$. Extract (i.e., the eluate from the first chromatogram) was dissolved in $85 \mu 1$. methanolchloroform (1:1) and 5 and $25 \mu 1$., respectively (corresponding to 100 and $500 \mu \mathrm{g}$. substance) were dropped on the start line of two adjacent paper strips (Whatman No. 1, dimensions and setting out as in Figure 3). On similar paper strips $5,10,2 \times 10$, and $3 \times 10 \mu 1$. of a 0.01 per cent methanolic solution of hydrocortisone (corresponding to $0.5,1,2$, and $3 \mu \mathrm{g}$.) were dropped, as well as $10 \mu \mathrm{l}$. of a 0.05 per cent solution of hydrocortisone (corresponding to $5 \mu \mathrm{g}$.) and $10 \mu \mathrm{l}$. of a 0.1 per cent solution of cortisone. The strips were hung immediately in the dry trough of the chromatography tank, well saturated with the phases of Bush's solvent system $C$, and equilibrated at the temperature at which the chromatogram is to be run (preferably $40^{\circ} \mathrm{C}$.). The solvent was then run into the trough. After the solvent front had reached the lower edge of the paper (about $2 \mathrm{hrs}$., observed by means of a little Sudan dye running simultaneously), the strips were removed, and allowed to dry for about an hour in air away from light.

For the evaluation of the chromatogram two combined color reactions are used, one depending on the reducing $\alpha$-ketol side chain, the other on the $\Delta^{4}$-3-ketone group in aldosterone. The strips are quickly dipped in an alkaline solution of blue tetra- 
zolium contained in a well-filled shallow dish, then with the aid of a glass rod laid directly on a white opaque glass plate and evaluated within 5 minutes. In a very short time, blue to violet spots appear wherever there are reducing compounds. Aldosterone separates readily from cortisone in Bush system $C$, but runs at practically the same rate as hydrocortisone from which it has, of course, already been separated in the preparative chromatogram. Therefore, a blue spot in the same position as hydrocortisone on the second chromatogram indicates, together with the sodium hydroxide fluorescence (see below), the presence of aldosterone. In the case of normal urine, the aldosterone content is so small (about 1 to $9 \mu \mathrm{g}$. per 24 hours) that usually a weak spot appears only in the $500 \mu \mathrm{g}$. chromatogram, while in hyperaldosteronuria, distinct spots may be seen in the $100 \mu \mathrm{g}$. chromatogram. The sensitivity limit of the blue tetrazolium reaction of aldosterone is about $0.2 \mu \mathrm{g}$. per $\mathrm{cm} .^{2}$ of the chromatogram. The aldosterone spots, located above the cortisone spots, are visually correlated against the hydrocortisone spots. (The slight differences between the sensitivities of aldosterone, cortisone, and hydrocortisone are insignificant for this semiquantitative estimation.)

After one-half to one hour, the strips are rapidly dried, hanging for 15 to 20 minutes in a drying oven at $90^{\circ} \mathrm{C}$. in a weak draught, and then observed in U.V. light from a mercury vapor lamp fitted with a filter (max. radiation at 300 to $370 \mathrm{~m} \mu$ ). In place of the blue formazan spots, a yellow fluorescence is seen wherever $\Delta^{4}$-3-ketosteroids are present. The spots drift somewhat during the drying process, which does not, however, affect the visual estimation under the U.V. lamp. The sensitivity of this soda-fluorescence reaction depends on the drying conditions and is optimally about $0.1 \mu \mathrm{g}$. per $\mathrm{cm}^{2}$ of the chromatogram. The same sensitivity can be obtained by an appropriate drying procedure with an infrared lamp. The variation between this estimation and that obtained with blue tetrazolium should not be more than 50 per cent for low concentrations, and not more than 30 per cent for higher concentrations. If there is a comparatively large discrepancy, the lower value only should be taken, otherwise the mean of the two determinations. Normally the values found by the soda fluorescence are somewhat lower than those by the blue tetrazolium reaction. By the use of both tests, the standard deviation can be kept below \pm 20 per cent for concentrations of 1 to $5 \mu \mathrm{g}$. per spot ( 2 to $3 \mathrm{~cm}^{2}$ ).

Example

Reduction test

$\mathrm{NaOH}$ test

Mean value

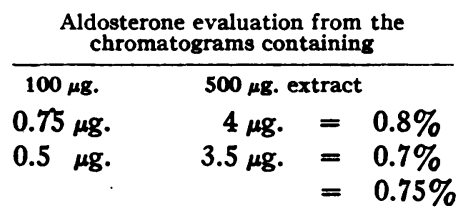

In this case the smallest margin of error was expected from the $\mathbf{5 0 0 \mu g}$. chromatograms, so the mean value from these alone was used in the estimation. For $1.7 \mathrm{mg}$. eluate from $900 \mathrm{ml}$. urine, this corresponds to $12.8 \mu \mathrm{g}$. per $900 \mathrm{ml}$., and with $1,150 \mathrm{ml}$. per 24 hours, to $15.4 \mu \mathrm{g}$. per 24 hours, or in round figures, to $15 \mu \mathrm{g}$. per 24 hours.

\section{DISCUSSION}

\section{a) Hydrolysis and extraction}

The aldosterone excreted with the urine is present to a large extent in a bound state (2). On the one hand the hydrolysis at $\mathrm{pH} 1$ for 24 hours (method d) has been shown (2) to release more aldosterone than that at $\mathrm{pH} 1$ for only about 30 to 60 minutes (method $\mathrm{c}$ ) or with $\beta$-glucuronidase (method $b$ ). On the other hand, free aldosterone is not completely stable at $\mathrm{pH} 1$ over 24 hours (8). A small amount of aldosterone released by method $d$ may therefore be assumed to be destroyed. A comparison of method $c$ and $d$, whereby free aldosterone was added to urine, showed that with method d, 10 to 15 per cent aldosterone is lost. Nevertheless, using a double extraction, first by method c when practically no aldosterone is destroyed $(8,9)$, then by method $\mathrm{d}$; the recovery of relatively small amounts of aldosterone excreted with the urine was hardly any better than with method $\mathrm{d}$ alone. The main bulk of the aldosterone is, in fact, not extractable under the inadequate hydrolytic conditions of method c, but is liberated only in method d, and therefore still exposed to the 24-hour-action of the acid. Moreover, it seems likely that the bound form of aldosterone is less affected by the acid than the free hormone. Finally, the time-consuming double extraction yields a larger amount of inert material which requires more paper sheets for the preparative chromatography, thereby causing additional losses (see below). For these reasons we use only method $d$. 


\section{b) Chromatography}

The losses in the preparative paper chromatography in formamide/chloroform (including the elution) were investigated. Samples of 2 and $20 \mu \mathrm{g}$. pure aldosterone added to $10 \mathrm{mg}$. each of an aldosterone-free extract prepared by method $d$ from the urine of a patient with Addison's disease were chromatographed and eluted. On average, 83 and 92 per cent, respectively, of aldosterone were recovered. The losses caused by both chromatography and elution are thus more important for low aldosterone concentrations than for higher ones. This result implies that the loss also depends on the number of sheets used. It is therefore advantageous in a series of experiments always to use the same number of sheets for the preparative chromatography, i.e., as far as possible the same urine equivalent per determination.

\section{c) Total yield and reproducibility.}

Five, 10 and $20 \mu \mathrm{g}$. aldosterone, respectively, were added to $500-\mathrm{ml}$. amounts of normal urine. The samples were frozen for 3 to 7 days, then thawed and worked up by the present method, two sheets of paper being used for each determination (quantity of extract 12.2 to $22.6 \mathrm{mg}$.). After subtracting the aldosterone originally present in the urine, averages of 68,76 and 86 per cent, respectively, of aldosterone were recovered depending on the amount added, the average thus being 75 per cent for this order of concentration. It should be mentioned that seemingly small variations of method can in some cases diminish the yield considerably. The reproducibility of the determinations under carefully standardized conditions was satisfactory, the standard deviation being less than \pm 20 per cent. If the amounts of aldosterone were very small, or when separate estimations were carried out by different operators, the standard deviation was as high as \pm 25 to 30 per cent.

The aldosterone extractable by the present method is estimated accurately enough for clinical purposes. However, the total aldosterone content in the urine remains somewhat uncertain, since the type of conjugation of aldosterone in the urine, and the absolute effectiveness of the hydrolysis is not sufficiently known.

\section{d) Results}

In comparison with the biological test methods, we have obtained slightly higher values. We ascribe this particularly to the possibility that in biological testing of the extracts, even when chromatographed, unknown factors with antagonizing activity are involved (10). In some cases this assumption could be confirmed, as we were able, despite low biological results, to isolate a high amount of crystalline aldosterone that corresponded to that found in the physicochemical test $(1,11,12)$. Moreover, Llaurado's very low recovery value of 20 per cent of the added aldosterone (13), determined biologically, could be eventually explained by such antagonistic substances. Finally it must be emphasized that we consider the use of two different solvent systems essential for the complete separation of the aldosterone.

The aldosterone excreted by healthy adults and determined by our method lies mostly between 1 to $9 \mu \mathrm{g}$. per 24 hours (14), or 0.5 to $6.5 \mu \mathrm{g}$. per 24 hours (15), as against 1.5 to $5 \mu \mathrm{g}$. (16) and 1 to $3 \mu \mathrm{g}$. (17) found in biological tests and with slightly different extraction and chromatography techniques. In 52 estimations in 16 persons who were clinically quite normal the range was 0.5 to $12.5 \mu \mathrm{g}$. per 24 hours $(P=0.05)$. In this connection it must be remembered that aldosterone excretion is closely related to the water, sodium and potassium intake, as well as to the renal and extrarenal water excretion (18-20). If these are not defined beforehand, it will be difficult to make a clear distinction between normal and slightly raised values.

The results obtained with this method in various illnesses (14), for instance in congenital adrenogenital syndrome $(10)$, in cirrhosis of the liver $(21,15)$, in hyperaldosteronuria, produced by a potassium load or by perspiration (18), and in postoperative patients (22), have been reported in part elsewhere.

\section{SUM MARY}

A detailed description of a specific, physicochemical method for the determination of aldosterone in the urine is given. Errors due to loss and variation are discussed, as well as the possible differences between the results using our method 
and those using biological test methods. Values for urines of normal adults are given.

\section{REFERENCES}

1. Luetscher, J. A., Jr., Neher, R., and Wettstein, A., Isolation of crystalline aldosterone from the urine of patients with congestive heart failure. Experientia, 1956, 12, 22.

2. Neher, R., and Wettstein, A., Physicochemical detection and measurement of aldosterone in body fluids and tissues. Acta endocrinol., 1955, 18, 386.

3. Zaffaroni, A., Micromethods for the analysis of adrenocortical steroids. Recent Progr. Hormone Res., 1953, 8, 51.

4. Cramer, F., Papierchromatographie. 3. Aufl., Verlag Chemie, Weinheim, 1954.

5. Block, R. J., Durrum, E. L., and Zweig, G., A Manual of Paper Chromatography, and Paper Electrophoresis. New York, Academic Press, 1955.

6. Bush, I. E., Chromatography of steroids and sterols. Brit. M. Bull., 1954, 10, 229.

7. Markham, R., and Smith, J. D., Chromatographic studies of nucleic acids. I. A technique for the identification and estimation of purine and pyrimidine bases, nucleosides and related substances. Biochem. J., 1949, 45, 294.

8. Simpson, S. A., Tait, J. F., Wettstein, A., Neher, R., von Euw, J., Schindler, O., and Reichstein, T., Aldosteron. Isolierung und Eigenschaften. Uber Bestandteile der Nebennierenrinde und verwandte Stoffe. Helvet. chim. acta, 1954, 37, 1163.

9. Venning, E. H., Giroud, C. J., Dyrenfurth, I., and Beck, J. C., Studies with aldosterone. Canad. J. Biochem. Physiol., 1955, 33, 605.

10. Prader, A., Spahr, A., and Neher, R., Erhöhte Aldosteronausscheidung beim kongenitalen adrenogenitalen Syndrom. Ein Beitrag zur Pathogenese des Syndroms. Schweiz. med. Wchnschr., 1955, 85, 1085.

11. Luetscher, J. A., Jr., Neher, R., and Wettstein, A., Isolation of crystalline aldosterone from the urine of a nephrotic patient. Experientia, 1954, 10, 456.
12. Luetscher, J. A., Jr., Dowdy, A., Harvey, J., Neher, R., and Wettstein, A., Isolation of crystalline aldosterone from the urine of a child with the nephrotic syndrome. J. Biol. Chem., 1955, 217, 505.

13. Llaurado, J. G., Increased excretion of aldosterone immediately after operation. Lancet, 1955, 1, 1295.

14. Wettstein, A., Ueber Aldosteron, in Lettré-InhoffenTschesche's handbook "Ueber Sterine, Gallensäuren und verwandte Naturstoffe," Vol. 2, Enke Stuttgart, 1956, In press.

15. Wolff, H. P., Koczorek, K. R., Jesch, W., and Buchborn, E., Untersuchungen über die AldosteronAusscheidung bei Leberkranken. Klin. Wchnschr., 1956, 34, 366.

16. Venning, E. H., Dyrenfurth, I., Giroud, C. J. P., and Beck, J. C., Clinical studies on the excretion of aldosterone. Montreal Physiolog. Soc. Proc., 17 Jan. 1955.

17. Axelrad, B. J., Cates, J. E., Johnson, B. B., and Luetscher, J. A., Jr., Aldosterone in urine of normal man and of patients with oedema. Its increased recovery after hydrolysis with acid and with betaglucuronidase. Brit. M. J., 1955, 1, 196.

18. Falbriard, A., Muller, A. F., Neher, R., and Mach, R. S., Etude des variations de l'aldostéronurie sous l'effet de surcharges en potassium et de déperditions rénales et extrarénales de sel et d'eau. Schweiz. med. Wchnschr., 1955, 85, 1218.

19. Luetscher, J. A., Jr., and Curtis, R. H., Aldosterone: Observations on the regulation of sodium and potassium balance. Ann. Int. Med., 1955, 43, 658.

20. Mach, R. S., Fabre, J., Muller, A. F., and Neher, R., Oedèmes per rétention de chlorure de sodium avec hyperaldostéronurie. Schweiz. med. Wchnschr., 1955, 85, 1229.

21. Wolff, H. P., and Koczorek, K. R., Uber die Ausscheidung von Aldosteron im Harn von Patienten mit Hepatitis epidemica und Lebercirrhose. Klin. Wchnschr., 1955, 33, 1104.

22. Llaurado, G. J., Neher, R., and Wettstein, A., Chemical identification of aldosterone in postoperative urine. Clin. chim. acta, 1956, In press. 